\title{
Clinical Significance of Intraluminal Contrast Enhancement in Patients with Spontaneous Cervical Artery Dissection: A Black-Blood MRI Study
}

\author{
Klinische Relevanz der intraluminalen \\ Kontrastmittelaufnahme bei Patienten mit spontaner \\ arterieller Dissektion der Halsgefäße: eine Black-Blood \\ MRT-Studie
}

Authors

Eva Coppenrath ${ }^{1}$, Olga Lenz ${ }^{1}$, Nora Sommer ${ }^{1}$, Nina Lummel${ }^{2}$, Jennifer Linn ${ }^{3}$, Karla Treitl ${ }^{1}$, Fabian Bamberg ${ }^{4}$, Maximilian Reiser ${ }^{1}$, Thomas Pfefferkorn ${ }^{5}$, Tobias Saam ${ }^{6}$

Affiliations

1 Institute of Clinical Radiology, Ludwig-MaximiliansUniversity Munich, Munich, Germany

2 Institute of Neuroradiology and Interventional Neuroradiology, University Hospital Klinikum rechts der Isar Munich, Munich, Germany

3 Institute of Neuroradiology, University Hospital Carl Gustav Carus, Dresden, Germany

4 Diagnostical and Interventional Radiology, Eberhard Karls University Tuebingen, Tuebingen, Germany

5 Interdisciplinary Stroke Center Munich, LudwigMaximilians-University Munich, Munich, Germany

6 Radiology Center Rosenheim, Rosenheim, Germany

Key words

carotid arteries, dissection, brain, vertebral arteries, MR angiography

received 13.11 .2016

accepted 05.02.2017

Bibliography

DOI http://dx.doi.org/10.1055/s-0043-104632

Published online: 26.4.2017 | Fortschr Röntgenstr 2017; 189: 624-631 @ Georg Thieme Verlag KG Stuttgart · New York

ISSN 1438-9029

Correspondence

Dr. Eva Coppenrath

Institut für klinische Radiologie, Ludwig- Maximilians-

Universität München

Ziemssenstr. 1

80336 Munich

Germany

Tel.: ++49/89/51609124

Fax: $++49 / 89 / 51609122$

eva.coppenrath@med.uni-muenchen.de

\section{ZUSAMMENFASSUNG}

Ziel Kürzlich durchgeführte Studien zeigten, dass intraluminale Thromben der A. carotis interna in black-blood (BB)-MRSequenzen eine Kontrastmittelaufnahme zeigen. Ziel der Studie ist es, die Wertigkeit der intraluminalen Kontrastmittelaufnahme bei Patienten mit einer spontanen arteriellen Dissektion der Halsgefäße zu untersuchen.

Material und Methoden 33 Patienten mit spontaner arterieller Dissektion der Halsgefäße (sCAD) erhielten ein MRT des Kopfes (Diffusion, T2w, T2* w, FLAIR) und eine 3T-MRT- Untersuchung der Halsgefäße mit hochaufgelösten fettgesättigten BB Sequenzen vor und nach Kontrastmittelgabe, sowie einer TOF-Sequenz. Nachweis oder Abwesenheit einer intraluminalen Kontrastmittelaufnahme (iCE), eines Gefäßverschlusses und eines Gefäßwandhämatoms (hyperintenses Signal in T1w vor Kontrastmittelgabe) wurden von zwei Radiologen im Konsensus untersucht.

Ergebnisse In 44 von 132 bewerteten Gefäßen wurde ein Gefäßwandhämatom gefunden, vereinbar mit einer sCAD. Bei 17 von 44 disseziierten Gefäßen wurde in der Hirn-MRT ein akuter Schlaganfall auf derselben Seite diagnostiziert. 16 von 17 (94,1\%) dieser Gefäße ipsilateral des Schlaganfalls zeigten ein iCE, verglichen mit 9 von 44 (20,4\%) disseziierten Gefäßen ohne Nachweis eines Schlaganfall $(p<0,001)$. Die Auswertung (Nachweises oder Abwesenheit von iCE) ergab eine Sensitivität, eine Spezifität, einen positiven bzw. negativen prädiktiven Wert sowie eine Accuracy von 0,94; 0,67, 0,64 und 0,95 und 0,77, sowie eine Odds ratio von 32,0.

Schlussfolgerung iCE scheint eine intraluminale Thrombosierung anzuzeigen, die streng korreliert ist mit ischämischen Symptomen bei Patienten mit einer sCAD.

\section{Kernaussagen}

- Bei Patienten mit arterieller Dissektion der Halsgefäße korreliert die intraluminale Kontrastmittelaufnahme mit einer umschriebenen Hirn-Ischämie im entsprechenden Gefäßterritorium. 
- Unsere Ergebnisse suggerieren, dass die intraluminale Kontrastmittelaufnahme eine intraluminale Thrombusbildung widerspiegelt.

- Die Untersuchung von Dissektionspatienten mittels blackblood-Sequenzen könnte dazu beitragen, Patienten mit einem hohen Schlaganfallrisiko zu erkennen.

\section{ABSTRACT}

Purpose Recent studies have suggested that intraluminal thrombi show contrast enhancement on carotid black-blood T1w MRI. The aim of this study was to evaluate the significance of intraluminal contrast enhancement (iCE) regarding symptom status in patients with spontaneous cervical artery dissection (sCAD).

Methods 33 consecutive patients (19 men) with sCAD received a brain MRI (DIFF, T2w, T2 ${ }^{*}$ w, FLAIR) and a multi-sequence 3T-MRI with fat-saturated high-resolution black-blood T1w-sequences pre- and post-contrast, contrast-enhanced MR angiography and TOF images of carotid and vertebral arteries. Presence/absence of iCE, vessel occlusion and vessel wall hematoma (hyperintense in $\mathrm{T} 1 \mathrm{w}$ pre-contrast) were analysed by two radiologists in consensus decision.

Results 44 of 132 analysed vessels had a vessel wall hematoma, consistent with sCAD. In 17 of 44 dissected vessels an acute ischemic stroke was found. 16 of 17 (94.1\%) vessels ip- silateral to ischemic stroke demonstrated iCE, compared to 9 of $44(20.4 \%)$ dissected vessels without stroke $(P<0.001)$. The presence/absence of iCE resulted in a sensitivity, specificity, positive and negative predictive value and accuracy for ischemic stroke of $0.94,0.67,0.64,0.95$, and 0.77 , respectively, and an odds ratio of 32.0 .

Conclusion iCE, which is suggestive of intraluminal thrombus formation, is strongly correlated with ischemic symptoms in patients with SCAD.

\section{Key points}

- Intraluminal contrast enhancement is associated with cerebral ischemia in corresponding vessel territories in patients with cervical artery dissection.

- Our results suggest that intraluminal contrast enhancement represents intraluminal thrombus formation.

- Black-blood imaging might be useful to identify those patients with cervical artery dissection at higher risk for initial or recurrent stroke.

\section{Citation Format}

- Coppenrath E, Lenz O, Sommer N et al. Clinical Significance of Intraluminal Contrast Enhancement in Patients with Spontaneous Cervical Artery Dissection: A Black-Blood MRI Study. Fortschr Röntgenstr 2017; 189: 624-631

\section{Introduction}

Cervical artery dissection (CAD) can provoke a variety of often nonspecific neurological symptoms such as headache/migraine, neck pain, Horner`s syndrome or other cranial nerve anomalies [1] and is an increasingly recognized cause of ischemic stroke, particularly in younger patients [2]. Although the majority of patients with CAD have a good prognosis, it is unclear why some patients suffer a stroke [3] and why some patients develop a stroke during follow-up [4]. Several hypotheses for the pathogenesis of spontaneous cervical artery dissection (SCAD) have been formulated:

One theory presumes a spontaneous rupture of the vasa vasorum of the artery which leads to pseudoaneurysms or rupture if the defect is located between the adventitia and media of the arterial wall $[5,6]$ or to stenosis or occlusion if located between the intima and media. Another theory suggests the creation of an intimal tear, which allows the entry of blood into the defect which then forms the vessel wall hematoma [7]. In sCAD abnormalities of the connective tissue [8] and association with vessel wall inflammation [9] have been discussed as predisposing factors for their occurrence.

Early diagnosis of CAD is of utmost importance and MRI has become a first-line diagnostic tool for $\operatorname{CAD}[10,11]$. Previous studies have shown that high-resolution black-blood (bb) MRI is ideally suited to visualize acute CAD, as it offers excellent visualization of the lumen, wall and peri-adventitial tissue and it allows visualization of the intimal tear noninvasively $[12,13]$. The separation of the intimal layer of the vessel wall may lead to endothelium dam- age and the activation of blood clotting which ultimately may lead to thrombus formation $[10,14]$. Thrombosis in the dissected arterial segment may then lead to vessel occlusion or embolization further downstream.

In CAD fat-suppressed T1w sequences reveal the characteristic hyperintense signal which represents the vessel wall hematoma (crescent sign) $[15,16]$. bb-MRI suppresses the signal of flowing blood which allows differentiation of the vessel wall and its components from the lumen, which appears dark. This technique has been used successfully for carotid plaque imaging [17], for the detection of venous thrombi [18] and for the visualization of CAD [13, 19-21]. It has also been used successfully to image plaque rupture and local blood coagulation in carotid atherosclerotic plaques [12, 17, 18, 22, 23].

Our own observations of occluded vessels in patients with spontaneous cervical artery dissection (sCAD) and Takayasu vasculitis and recent studies in venous thrombi (look for venous thrombosis of the intracranial veins with the SPACE sequence) have suggested that intra-luminal thrombi are characterized by intraluminal contrast enhancement (iCE) on T1w-bb-MRI. The aim of the study was to evaluate the association of iCE with ischemic stroke in patients with sCAD. 


\section{Materials and Methods}

\section{Patients}

Patients with sCAD treated at our center between August $23^{\text {rd }}$ 2007 and June $29^{\text {th }} 2010$ were prospectively included in the study if the following inclusion criteria were fulfilled:

1. Clinical suspicion of CAD and evidence of vessel wall hematoma on standard neck MRI (hyperintense signal on fat-suppressed T1w sequences demonstrating intramural methemoglobin accumulation and stenosis or occlusion in contrast-enhanced (CE) MR angiography)

2. Performance of standard brain MRI consisting of fluid-attenuated inversion recovery sequence (FLAIR), T2-weighted sequence (T2w), diffusion-weighted sequences (Diff), $3 \mathrm{D}$ timeof-flight sequence (TOF)

3. Written informed consent, and

4. Performance of high-resolution fat-suppressed T1w-bb-MRI within 1 week after standard brain and neck MRI diagnostics.

The study was approved by the local institutional ethics committee and complied with the Declaration of Helsinki.

\section{MRI}

Patients with clinical suspicion of sCAD were routinely examined with a 1.5 T Symphony ${ }^{\circledR}$ (Siemens Medical Solutions, Erlangen, Germany) or a 3.0 T GE scanner (Signa ${ }^{\circledR}$ HDxt, GE Healthcare, Milwaukee, WI, USA) using a standard head and neck coil.

Standard neck sequences included fat-suppressed (fs) T1w sequences with a slice thickness of $3.5 \mathrm{~mm}(1.5 \mathrm{~T})$ or $3.0 \mathrm{~mm}$ ( $3 \mathrm{~T})$ in the coronal and axial plane and contrast-enhanced MR angiography $(C E-M R A)$ with a pixel size of $0.84 \times 0.84 \mathrm{~mm}^{2}(1.5 \mathrm{~T})$ or $1.0 \times 1.0 \mathrm{~mm}^{2}$ (3 T) (fs T1 $\mathrm{w}$ and CE-MRA = standard neck MRI). Maximum intensity projections (MIP) were carried out for the representation of CE-MRA. The contrast medium Gadobutrol (Gadovist ${ }^{\circledR}$, Bayer Vital, Leverkusen, Germany) was applied in a dose of $0.1 \mathrm{mmol} / \mathrm{kg}$ body weight. In the same examination a standard brain MRI was performed to document any cerebral lesion. Clinical symptoms, patient history and evidence of CAD in these initial MRI scans resulted in the diagnosis of sCAD.

Within one week a multi-sequence $3 \mathrm{~T}$ high-resolution MRI scan (Verio ${ }^{\circledR}$, Siemens Medical Solutions, Erlangen, Germany) with a flexible 4-channel carotid surface coil (Machnet BV, Eelde, ND) [9] was executed consisting of fat-saturated T1w-bb-sequences pre- and post-contrast. High resolution was defined as a spatial resolution with an in-plane pixel size of $0.5 \times 0.5 \mathrm{~mm}^{2}$ and a slice thickness of $2 \mathrm{~mm}$. The image parameters are listed in - Table 1.

\section{Image Analysis}

The presence or absence of iCE, vessel occlusion and vessel wall hematoma on T1w-bb images pre- and post-contrast of both carotid and both vertebral arteries were reviewed by two experienced radiologists in consensus decision (T.S; E.C.). The radiologists were blinded to all clinical information and the standard brain MRI. Image quality was rated as followed: 4 = excellent, uni-
- Table 1 Sequence parameters of the high-resolution black-blood T1w sequence.

- Tab. 1 Sequenzparameter der hochaufgelösten black-blood T1w-Sequenz.

\begin{tabular}{|c|c|}
\hline & hr-bb-T1w \\
\hline field strength (tesla) & 3 \\
\hline sequence & 2D-TSE \\
\hline ECG gating & none \\
\hline fat suppression & yes \\
\hline TR (ms) & 800 \\
\hline TE (ms) & 12 \\
\hline PAT factor & 2 \\
\hline ETL & 11 \\
\hline flip angle $\left(^{\circ}\right)$ & 180 \\
\hline averages & 2 \\
\hline $\mathrm{FOV}\left(\mathrm{mm}^{2}\right)$ & $160 \times 120$ \\
\hline matrix & $240 \times 320$ \\
\hline number of slices & 15 \\
\hline slice thickness (mm) & 2.0 \\
\hline pixel size $\left(\mathrm{mm}^{2}\right)$ & $0.5 \times 0.5$ \\
\hline imaging time per slice & $0: 19$ \\
\hline total (minutes) & $4: 38$ \\
\hline flow suppression & DIR \\
\hline \multicolumn{2}{|c|}{$\begin{array}{l}\text { hr-bb = high-resolution black-blood; } T S E=\text { turbo spin echo; } E C G=\text { elec- } \\
\text { trocardiogram, } T R=\text { time to repetition, } T E=\text { time to echo; } P A T=\text { parallel } \\
\text { acquisition technique, ETL = echo train length, FOV = field of view, } \\
\text { DIR = double inversion recovery }\end{array}$} \\
\hline
\end{tabular}

form image; 3 =good, minimal heterogeneity, only minor flow artifacts; 2 = satisfactory, delineated lumen, noticeable flow artifacts; 1 = not suitable for diagnosis. Diagnostic confidence was rated as 4 = excellent, exact diagnosis possible; 3 = good, with definite diagnosis possible; 2 = fair, judgement of major findings possible; 1 = poor with definite diagnosis not possible. A vessel wall hematoma was defined as an area of hyperintense signal intensity on pre-contrast T1w-bb images in the vessel wall. Additional criteria for vessel wall hematoma were a crescent-shaped hyperintensity and/or an intimal flap best seen on TOF images. iCE was defined as an area of intraluminal contrast enhancement on post-contrast T1w-bb images. Vessel occlusion was identified by a filling defect on MRA images.

\section{Statistics}

Statistical analysis was carried out with SPSS version 20.0 (SPSS Inc., Chicago, IL, USA). To correlate the parameters "iCE/stroke", "iCE/vessel occlusion", and "vessel occlusion/stroke", standard $4 \times 4$ contingency tables were used to calculate the sensitivity, specificity, positive predictive value, negative predictive value, accuracy and odds ratio. Differences in distribution regarding catego- 
- Table 2 Patient characteristics.

- Tab. 2 Patientencharakteristik.

$$
\text { patients }(n=33)
$$

\begin{tabular}{|l|c|}
\hline age (years) & $47.0 \pm 12.1$ \\
\hline male sex, $\mathrm{n}(\%)$ & $19(58)$ \\
\hline body mass index $\left(\mathrm{kg} / \mathrm{m}^{2}\right)$ & $24.3 \pm 4.4$ \\
\hline smoking history ${ }^{1}, \mathrm{n}(\%)$ & $18(56)$ \\
\hline hypertension, $\mathrm{n}(\%)$ & $12(35)$ \\
\hline hypercholesterolemia, $\mathrm{n}(\%)$ & $10(29)$ \\
\hline coronary heart disease, $\mathrm{n}(\%)$ & $2(6)$ \\
\hline diabetes mellitus, $\mathrm{n}(\%)$ & $0(0)$ \\
\hline family history of cardiovascular disease, $\mathrm{n}(\%)$ & $3(10)$ \\
\hline symptoms of cervical artery dissection: & $17(52)$ \\
\hline stroke, $\mathrm{n}(\%)$ & $4(12)$ \\
\hline Horner Syndrome, $\mathrm{n}(\%)$ & $10(30)$ \\
\hline headache, $\mathrm{n}(\%)$ & $4(12)$ \\
\hline paresthesia, $\mathrm{n}(\%)$ & $3(9)$ \\
\hline others, $\mathrm{n}(\%)$ & \\
\hline 1 Smoking history: former and current smoking. & \\
\hline
\end{tabular}

rical variables, such as risk factor profiles, were analyzed using the Fisher's exact test. A p-value of $<0.05$ was considered to be statistically significant.

\section{Results}

33 patients with sCAD fulfilled the inclusion criteria. $>$ Table 2 gives an overview of the demographics, clinical presentation and cardiovascular risk factors. The mean age was $47 \pm 12.1$ years. Dissections were found in 19 men and 14 women (58/42\%). In 33 patients 132 vessels were evaluated ( 2 carotid and 2 vertebral arteries per patient). 44 out of 132 analyzed vessels showed a vessel wall hematoma consistent with CAD. 23 patients had one dissection, 9 patients two and one patient three dissections ( $\vee$ Table 3 ). The location of the dissected arterial segments is given in $>$ Table 4 using the Bouthillier classification. About two-thirds of the dissections were located in the internal carotid artery ( $p=0.07$, not significant, $\triangleright$ Table 3 ). Women were more likely to present with more than one dissection ( 3 men with $\geq$ two dissections compared to 7 women with $\geq$ two dissections, $\mathrm{p}<0.05$ ).

The image quality of T1w-bb sequences was found to be good or very good (mean: 3.7, range: $3-4$ ). Diagnostic confidence was rated even better (mean: 3.9, range: 3 -4). 17 strokes were found in the corresponding vessel territory of SCAD. There was a tendency to a higher prevalence of ischemic stroke in vessel territories of the internal carotid artery compared to the vertebral arteries ( $48 \%$ vs. $20 \%, p=0.068$, n.s.). 16 of these dissected arteries showed iCE in the dissected vessel segment, and one vessel
- Table 3 Location of dissections and prevalence of ischemic stroke.

- Tab. 3 Lokalisation der Dissektionen und Prevalence des Schlaganfalls.

\begin{tabular}{|l|l|l|l|}
\hline & & $\begin{array}{l}\text { internal } \\
\text { carotid artery }\end{array}$ & $\begin{array}{l}\text { vertebral } \\
\text { artery }\end{array}$ \\
\hline & location of dissections \\
\hline $\begin{array}{l}\text { patients } \\
(\mathbf{n}=\mathbf{3 3})\end{array}$ & dissections per patient & & \\
\hline 23 & 1 & 18 & 5 \\
\hline 9 & 2 & 10 & 8 \\
\hline 1 & 3 & 1 & 2 \\
\hline & & total $\mathrm{n}=29$ & total $\mathrm{n}=15$ \\
\hline stroke and vessel territories & & $14(48 \%)$ & $3(20 \%)$ \\
\hline stroke & & $15(52 \%)$ & $12(80 \%)$ \\
\hline no stroke * & & & \\
\hline
\end{tabular}

showed no iCE. In 9 dissected vessels without a stroke, iCE was detected in the dissected vessel segments. In 18 dissected vessels neither a stroke nor iCE could be found in the dissected vessel segments ( $\triangleright$ Table 5 ). Fisher`s exact test for association of iCE and stroke was highly significant $(p<0.001)$. iCE in the prediction of stroke showed a sensitivity of $94 \%$, a specificity of $67 \%$, a positive predictive value of $64 \%$, a negative predictive value of $95 \%$ and an accuracy of $77 \%$. The odds ratio was 32.0 (confidence interval $3.6-281)$.

In the 44 dissected vessel segments of our study, 15 segments showed occlusion. In 14 out of 15 occluded vessel segments, iCE could be found. Stroke was detected in the vessel territory of 12 occluded vessels and in 5 non-occluded dissected vessel segments. In three occluded vessel segments, no stroke was found. 24 dissected vessels were not occluded and did not reveal a stroke. In the Chi-square test a significant test result was observed for vessel occlusion/contrast enhancement and vessel occlusion/ stroke $(p<0.001)$. Fig. 1 - $\mathbf{3}$ show examples of CAD with and without iCE.

\section{Discussion}

In this mono-centric, prospective and observational study, we were able to show that the presence of iCE in patients with sCAD on T1w-bb images is highly associated with ischemic stroke in the corresponding vessel territory. In fact 16 out of 17 vessels with CAD and stroke in the corresponding vessel territory had iCE which in our opinion shows that iCE is indicative of intraluminal thrombus formation. This is supported by the finding that nearly all occluded vessels (14 out of 15) had iCE. However, iCE also occurred in non-occluded vessels and further studies are warranted to investigate the association of iCE in non-occluded vessels with sCAD and the risk of ischemic stroke or its reoccurrence. 
- Table 4 Dissected arterial segments (Bouthillier classification).

- Tab.4 Betroffene Gefäßabschnitte in der Klassifikation nach Bouthillier.

\begin{tabular}{|c|c|c|c|c|}
\hline sex & age & vessel & side & location \\
\hline $\mathrm{m}$ & 42 & ICA & right & C1 \\
\hline $\mathrm{m}$ & 62 & ICA & right & C2 \\
\hline \multirow[t]{2}{*}{$\mathrm{m}$} & 45 & ICA & left & $\mathrm{C} 1 / \mathrm{C} 2$ \\
\hline & & VA & right & V2/V3 \\
\hline $\mathrm{m}$ & 44 & ICA & right & C1-C3 \\
\hline $\mathrm{m}$ & 56 & ICA & left & C1-C6 \\
\hline $\mathrm{m}$ & 50 & ICA & left & $\mathrm{C} 1$ \\
\hline $\mathrm{m}$ & 66 & ICA & left & C1 \\
\hline $\mathrm{m}$ & 34 & ICA & left & $\mathrm{C} 2 / \mathrm{C} 3 / \mathrm{BIF}$ \\
\hline $\mathrm{m}$ & 55 & ICA & left & $\mathrm{C} 1 / \mathrm{C} 2$ \\
\hline $\mathrm{m}$ & 55 & ICA & left & $\mathrm{C} 1 / \mathrm{C} 2$ \\
\hline \multirow[t]{2}{*}{$\mathrm{m}$} & 52 & ICA & left & $\mathrm{C} 1 / \mathrm{C2}$ \\
\hline & & VA & right & V1/V2 \\
\hline $\mathrm{m}$ & 45 & ICA & left & C1-C5 \\
\hline \multirow[t]{2}{*}{$\mathrm{m}$} & 62 & VA & right & V3 \\
\hline & & VA & left & V3 \\
\hline $\mathrm{m}$ & 48 & VA & left & V3/V4 \\
\hline $\mathrm{m}$ & 59 & VA & right & V3 \\
\hline $\mathrm{m}$ & 50 & ICA & right & C1 \\
\hline $\mathrm{m}$ & 72 & VA & right & V4 \\
\hline $\mathrm{m}$ & 47 & ICA & left & C1 \\
\hline $\mathrm{m}$ & 43 & ICA & right & $\mathrm{C} 1 / \mathrm{C} 2 / \mathrm{BIF}$ \\
\hline w & 45 & ICA & right & C2 \\
\hline w & 44 & ICA & right & C2 \\
\hline \multirow[t]{3}{*}{ w } & 24 & ICA & right & C1 \\
\hline & & VA & right & V1 \\
\hline & & VA & left & V1 \\
\hline \multirow[t]{2}{*}{ w } & 41 & ICA & left & $\mathrm{C} 1$ \\
\hline & & VA & left & V2/V3 \\
\hline \multirow[t]{2}{*}{ w } & 34 & ICA & right & $\mathrm{C} 1$ \\
\hline & & VA & left & V2-V4 \\
\hline \multirow[t]{2}{*}{ w } & 35 & ICA & right & $\mathrm{C} 1 / \mathrm{C} 2 / \mathrm{BIF}$ \\
\hline & & ICA & left & $\mathrm{C} 1 / \mathrm{C} 2 / \mathrm{BIF}$ \\
\hline w & 43 & ICA & right & $\mathrm{C} 1 / \mathrm{BIF}$ \\
\hline w & 35 & VA & left & $\mathrm{V} 2 / \mathrm{V} 3$ \\
\hline w & 45 & ICA & right & $\mathrm{C} 2 / \mathrm{C} 3$ \\
\hline \multirow[t]{2}{*}{ w } & 46 & VA & right & V2 \\
\hline & & VA & left & V2 \\
\hline \multirow[t]{2}{*}{ w } & 63 & ICA & right & $\mathrm{C} 1 / \mathrm{C} 2$ \\
\hline & & ICA & left & $\mathrm{C} 1 / \mathrm{C2}$ \\
\hline
\end{tabular}

- Table 4 (Continuation)

\begin{tabular}{|l|l|l|l|l|}
\hline sex & age & vessel & side & location \\
\hline w & 33 & ICA & left & $\mathrm{C} 1 / \mathrm{C} 2$ \\
\hline w & 31 & VA & left & $\mathrm{V} 3 / \mathrm{V} 4$ \\
\hline w & 44 & ICA & right & $\mathrm{C} 1 / \mathrm{C} 2$ \\
\hline & & ICA & left & $\mathrm{C} 1$ \\
\hline
\end{tabular}

ICA: internal carotid artery; VA: vertebral artery; BIF: carotid bifurcation Bouthillier classification of dissected arterial segments ( $C 1=$ cervical segment, C2 = petrous segment, C3 = lacerum segment, C4 = cavernous segment, $C 5$ = clinoid segment, $C 6$ = supraclinoid [ophthalmic] segment, $\mathrm{C} 7$ = terminal [communicating] segment of ICA; V1 = preforaminal segment, V2 = foraminal segment, V3 = atlantic [extradural] segment, V4 = intradural segment of VA)

- Table 5 Intraluminal contrast enhancement in dissected vessels and stroke.

- Tab.5 Intraluminale Kontrastmittelaufnahme in den disseziierten Gefäßen und Auftreten eines Schlagafnall.

\begin{tabular}{|c|c|c|c|}
\hline & & \multicolumn{2}{|c|}{$\begin{array}{l}\text { intraluminal contrast } \\
\text { enhancement }\end{array}$} \\
\hline & & yes & no \\
\hline \multirow[t]{2}{*}{ stroke $^{1}$} & yes & 16 & 1 \\
\hline & no & 9 & 18 \\
\hline
\end{tabular}

Patient age and characteristics in our SCAD study were similar to previous studies [24]. In our investigation stroke was found in $52 \%$ of patients, which is consistent with the literature in which the stroke incidence in SCAD patients ranges from $20-60 \%$ [24, 25]. MRI is ideally suited to diagnose vessel wall hematoma. Although fat-suppressed T1w images without the use of contrast media are able to visualize the vessel wall hematoma, addition of bb-pre-pulses (e.g. double or quadruple inversion recovery= DIR or QIR) offer the advantage of the simultaneous assessment of intraluminal changes and the vessel wall [13]. This study showed that the combined assessment of the vessel wall and intraluminal changes with $\mathrm{T} 1 \mathrm{w}$-bb MRI is feasible and that this technique results in good to excellent image quality and yields a high diagnostic confidence level for the diagnosis of sCAD. In addition, to differentiate iCE from intraluminal flow artifacts, sufficient flow suppression is mandatory.

Previous observations in patients with SCAD and in patients with occluded vessels in Takayasu disease led us to believe that iCE on T1w-bb-MRI represents thrombus formation. In this study we therefore sought to evaluate the significance of iCE in patients with SCAD on clinical symptom status. The high correlation between iCE in the dissected vessel segments and stroke is in 

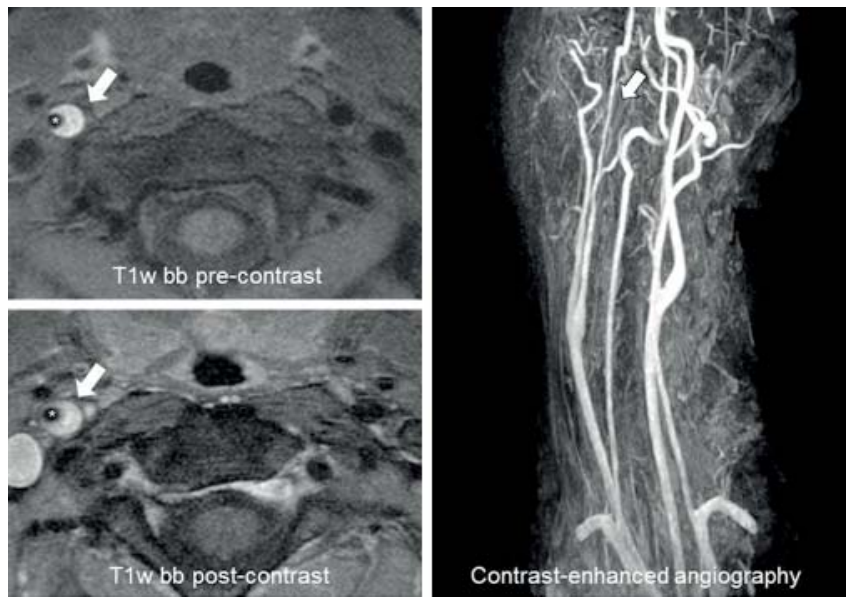

- Fig. 1 Fat-saturated high-resolution T1w black-blood sequence (T1w-bb) pre- (upper left) and post-contrast (lower left). A vessel wall hematoma is found in the right internal carotid artery (arrow) typical for cervical artery dissection. No intraluminal contrast enhancement is detected after contrast media application $\left({ }^{*}=\right.$ vessel lumen). This patient did not suffer from a stroke. Contrast-enhanced MR angiography depicts stenosis but no occlusion (right).

- Abb. 1 Fettgesättigte hochaufgelöste T1w-black-blood-Sequenz (T1w-bb) vor (oben links) und nach Kontrastmittelgabe (unten links). Ein Gefäßwandhämatom in der rechten A. carotis interna (Pfeil) ist erkennbar, typisch für eine arterielle Dissektion. Keine intraluminale Kontrastmittelaufnahme ist nach Kontrastmittelgabe $\left({ }^{*}=\right.$ Gefäßlumen $)$ erkennbar. Der Patient blieb schlaganfallsfrei. Die kontrastmittelgestützte MR-Angiografie zeigt eine Stenose, aber keine Okklusion (rechts).
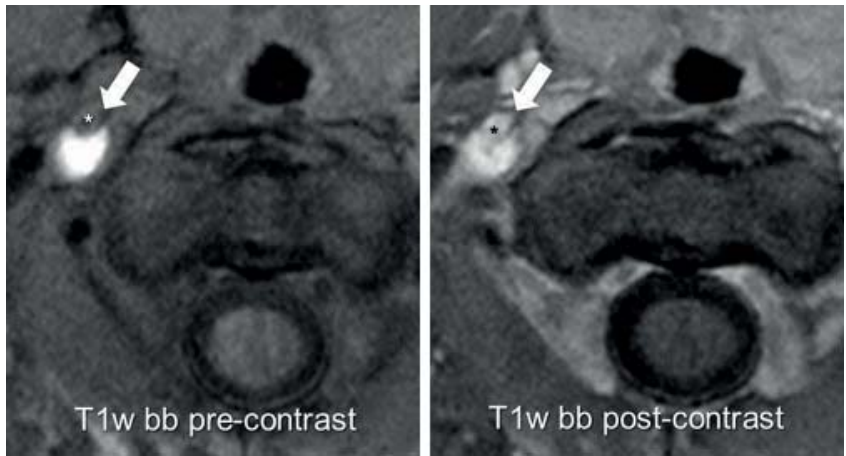

- Fig. 2 Fat-saturated high-resolution T1w black-blood images (T1w-bb) pre- (left) and post-contrast (right). A vessel wall hematoma can be seen in the right internal carotid artery (arrow), consistent with cervical artery dissection. After contrast media application, intraluminal contrast enhancement is revealed $\left({ }^{*}=\right.$ vessel lumen).

- Abb. 2 Fettgesättigte hochaufgelöste T1w-black-blood-Sequenz (T1w-bb) vor (links) und nach (rechts) Kontrastmittelgabe. Ein Gefäßwandhämatom ist in der rechten A. carotis interna erkennbar (Pfeil), vereinbar mit arterieller Dissektion. Nach Kontrastmittelgabe zeigt sich ein intraluminale Kontrastmittelaufnahme ${ }^{*}=$ Gefäßlumen $)$.
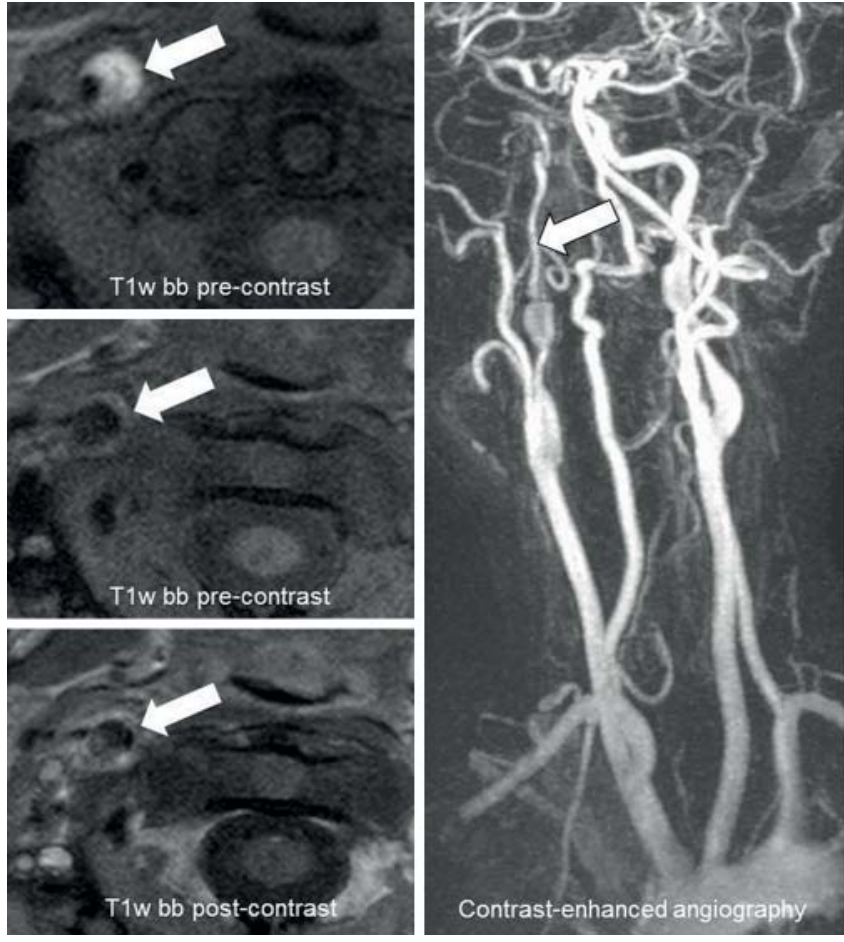

- Fig. 3 Dissection of the right carotid artery. On the left side the vessel wall hematoma can be seen (upper left) in fat-saturated highresolution T1w black-blood (T1w-bb) images. In adjacent slices T1w-bb pre- (middle left) and post-contrast (lower left) images reveal slight intraluminal contrast enhancement. No occlusion (contrast-enhanced angiography on the right) and no stroke were found.

- Abb. 3 Dissektion der rechten A. carotis interna. Auf der linken Seite ist das Gefäßwandhämatom in den fettgesättigten hochaufgelösten T1w-black-blood- (T1w-bb) Bildern zu sehen (oben links). In den angrenzenden Schichten ist in Zusammenschau der T1w-bbBilder vor (Mitte links) und nach Kontrastmittelgabe (unten links) eine leichte intraluminale Kontrastmittelaufnahme erkennbar. Keine Okklusion (Kontrastmittelgestützte MR-Angiografie rechts) und kein Schlaganfall konnten gefunden werden.

accordance with our hypothesis, although our study group is small. Information about the presence/absence of intraluminal thrombus is important as previous studies have shown that large infarcts causing death or severe disability were associated with a thrombus in the internal carotid artery and distal emboli [26].

Although the risk of recurrent stroke in CAD is generally considered to be low (stroke recurrence rates of $1-3 \%$ have been reported $[4,27])$, one could assume that patients with iCE have a higher risk for stroke recurrence compared to patients without iCE. One subgroup in our patient cohort without stroke might be particularly interesting: asymptomatic patients with iCE. These patients could have a higher risk of stroke compared to asymptomatic patients without iCE. It is known that a subset of patients with initially stroke-free SCAD suffer a stroke within the first weeks after occurrence of SCAD [28] which could be caused by thrombus formation. Whether certain subgroups of patients could profit from more aggressive anti-thrombotic therapy remains to be evaluated in future studies. Only trials much larger 
than ours could possibly answer this question. Because MRI is increasingly used in the routine diagnostic workup of CAD patients, high-resolution, contrast-enhanced, T1-weighted sequences could easily be included in a respective study protocol.

sCAD and severe ischemic stroke were more closely associated in the internal carotid compared to the vertebral arteries. This finding is consistent with the literature [29]. One possible explanation for this is that even in the case of total vessel occlusion the vertebral artery has good collateralization over the contralateral side. However, our results missed the level of significance $(p=0.07)$, probably due to the small number of patients.

\section{Limitations}

Our study is relatively small and larger studies are necessary to confirm these initially very promising results. Because of the good functional outcome in most of our patients, we cannot provide much information on the clinical, therapeutic, and prognostic relevance of $\mathrm{iCE}$ in SCAD patients in the long term. However, the association of iCE with ischemic stroke in the corresponding vessel territory suggests that iCE could be a potential imaging biomarker to identify patients with a possibly higher risk of adverse outcomes. The current study used $2 \mathrm{D}$ pre- and post-contrast T1w sequences which have a relatively large slice thickness of $2 \mathrm{~mm}$ and are time-consuming. For future studies of arterial dissection, 3D-T1w black-blood sequences such as 3D-T1w-VISTA or 3D-T1w-SPACE seem to be promising candidates as they provide superior coverage and sub-mm resolution. These sequences have already been applied successfully for thrombus imaging [18] and for vasculitis imaging [30]. Furthermore, we cannot provide histological proof that iCE represents thrombus formation which is due to the fact that histology is usually not obtained in SCAD patients. iCE can also be found in stenosed vessels or when slow flow occurs although - based on our clinical experience - the contrast enhancement in slow flow is lower and more focal and can therefore in most cases be easily differentiated from iCE in thrombi.

\section{Conclusion}

The presence of iCE in T1w-bb MR imaging is strongly correlated with ischemic events in the corresponding vessel territory in patients with sCAD, which is highly suggestive that iCE represents intraluminal thrombus formation. Future prospective studies will have to determine whether patients with iCE are at greater risk for recurrent stroke or a worse clinical outcome.

\section{CLINICAL RELEVANCE}

- Intraluminal contrast enhancement is correlated with ischemic events in patients with spontaneous cervical artery dissection.

- T1w-black-blood MR imaging provides a novel tool to detect intravascular thrombus formation.

- The results may be beneficial to triage patients with impending stroke.
Conflict of Interest

The authors declare that they have no conflict of interest.

References:

[1] Rist PM, Diener HC, Kurth T et al. Migraine, migraine aura, and cervical artery dissection: a systematic review and meta-analysis. Cephalalgia 2011; 31: 886-896

[2] Debette S, Leys D. Cervical-artery dissections: predisposing factors, diagnosis, and outcome. Lancet Neurol 2009; 8: 668-678

[3] Béjot $Y$, Baubail B, Debette $S$ et al. Incidence and outcome of cerebrovascular events related to cervical artery dissection in Dijon Stroke Registry. Int J Stroke 2014; 9: 879-882

[4] Weimar C, Kraywinkel K, Hagemeister C et al. Recurrent stroke after cervical artery dissection. J Neurol Neurosurg Psychiatry 2010; 81: 869-873

[5] Ro A, Kageyama N. Pathomorphometry of ruptured intracranial vertebral arterial dissection: adventitial rupture, dilated lesion, intimal tear, and medial defect. J Neurosurg 2013; 119: $221-227$

[6] Völker W, Besselmann M, Dittrich R et al. Generalized arteriopathy in patients with cervical artery dissection. Neurology 2005; 64: 1508 1513 Erratum 64(12): 2147

[7] Haneline MT, Rosner AL. The etiology of cervical artery dissection. Journal of chiropractic medicine 2007; 6: 110-120

[8] Brandt T, Hausser I, Orberk E et al. Ultrastructural connective tissue abnormalities in patients with spontaneous cervicocerebral artery dissections. Ann Neurol 1998; 44: $281-285$

[9] Pfefferkorn T, Saam T, Rominger A et al. Vessel wall inflammation in spontaneous cervical artery dissection. A prospective observational positron emission tomography, computed tomography, and magnetic Resonance imaging study. Stroke 2011; 42: 1563-1568

[10] Stence NV, Fenton LZ, Goldenberg NA et al. Craniocervical Arterial Dissection in Children: Diagnosis and Treatment. Curr Treat Options Neurol 2011; 13: 636-648

[11] Ben Hassen W, Machet A, Edjlali-Goujon M et al. (2014) Imaging of cervical artery dissection. Diagn Interv Imaging 2014; 95: 1151-1161

[12] Oppenheim C, Naggara O, Touzé E et al. High-resolution MR imaging of the cervical arterial wall: what the radiologist needs to know. Radiographics 2009; 29: 1413-1431

[13] Bachmann R, Nassenstein I, Kooijman $\mathrm{H}$ et al. (2007) High-resolution magnetic resonance imaging (MRI) at 3.0 Tesla in the short-term followup of patients with proven cervical artery dissection. Invest Radiol 2007; 42: $460-466$

[14] Tan MA, Armstrong D, MacGregor DL et al. Late complications of vertebral artery dissection in children: pseudoaneurysm, thrombosis, and recurrent stroke. J Child Neurol 2009; 24: 354-360

[15] Kuroda S, Abumiya T, Takahashi A et al. Magnetic resonance findings in spontaneous dissection of the cervical internal carotid artery - case report. Neurol Med Chir (Tokyo) 1992; 32: $773-777$

[16] Hinton DP, Cury RC, Chan RC et al. Bright and black blood imaging of the carotid bifurcation at 3.0T. Eur J Radiol 2006; 578: 403-411

[17] Saam T, Raya JG, Cyran CC et al. High resolution carotid black-blood 3T MR with parallel imaging and dedicated 4-channel surface coils. J Cardiovasc Magn Reson 2009; 11: 41

[18] Treitl KM, Treitl M, Kooijman-Kurfuerst $\mathrm{H}$ et al. Three-dimensional blackblood T1-weighted turbo spin-echo techniques for the diagnosis of deep vein thrombosis in comparison with contrast-enhanced magnetic resonance imaging: a pilot study. Invest Radiol 2015; 50: 401-408

[19] Edjlali M, Roca P, Rabrait C et al. 3D fast spin-echo T1 black-blood imaging for the diagnosis of cervical artery dissection. Am J Neuroradiol 2013; 34: E103-E106 
[20] Takano K, Yamashita S, Takemoto K et al. MRI of intracranial vertebral artery dissection: evaluation of intramural haematoma using a black blood, variable-flip-angle 3D turbo spin-echo sequence. Neuroradiology 2013; 55: $845-851$

[21] Habs M, Pfefferkorn T, Cyran CC et al. Age determination of vessel wall hematoma in spontaneous cervical artery dissection: a multi-sequence 3T cardiovascular magnetic resonance study. J Cardiovasc Magn Reson 2011; $13: 76$

[22] Saam T, Hetterich H, Hoffmann V et al. Meta-analysis and systematic review of the predictive value of carotid plaque hemorrhage on cerebrovascular events by magnetic resonance imaging. J Am Coll Cardiol 2013; 62: 1081 - 1091

[23] Esposito-Bauer L, Saam T, Ghodrati I et al. MRI plaque imaging detects carotid plaques with a high risk for future cerebrovascular events in asymptomatic patients. PLoS One 2013; 8: e67927

[24] Paciaroni M, Georgiadis D, Arnold M et al. Seasonal variability in spontaneous cervical artery dissection. J. Neurol. Neurosurg. Psychiatry 2006; 77: $677-679$
[25] Baumgartner RW, Arnold M, Baumgartner I et al. Carotid dissection with and without ischemic events: local symptoms and cerbral artery findings. Neurology 2001; 57: 827-832

[26] Bogousslavsky J, Despland PA, Regli I. Spontaneous carotid dissection with acute stroke. Arch. Neurol 1987; 44: 137-140

[27] Ntaios G, Lambrou D, Cuendet D et al. Early major worsening in ischemic stroke: predictors and outcome. Neurocrit Care 2013; 19: 287-292

[28] Lichy C, Metso A, Pezzini A et al. Predictors of delayed stroke in patients with cervical artery dissection. Int J Stroke 2015; 10: 360-363

[29] von Babo M, De Marchis GM, Sarikaya H et al. Differences and similarities between spontaneous dissections of the internal carotid artery and the vertebral artery. Stroke 2013; 44: 1537-1542

[30] Treitl KM, Maurus S, Sommer NN et al. 3D-black-blood 3T-MRI for the diagnosis of thoracic large vessel vasculitis: A feasibility study. Eur Radiol 2016; [Epub ahead of print] DOI: 10.1007/s00330-016-4525-x 